\title{
CORRECTION
}

\section{Correction to: A note on linear non-Newtonian Volterra integral equations}

\section{Nihan Güngör ${ }^{1}$}

Published online: 5 October 2021

(C) The Author(s), under exclusive licence to Islamic Azad University 2021

\section{Correction to: Mathematical Sciences https://doi.org/10.1007/s40096-021-00427-z}

Unfortunately, some of the corrections were missed in the original version and the corrections are as follows:

In Theorem 1, the highlighted text should be in italics

Theorem 1 Let $f, g: \dot{[} a, b] \rightarrow \mathbb{R}_{\beta}$ be $*$-continuous. Then, the following statements hold:

$$
\begin{aligned}
& \text { (1) } \quad * \int_{a}^{b}[\lambda \ddot{\times} f(x) \ddot{+} \mu \ddot{\times} g(x)] d^{*} x \\
& =\lambda \ddot{\times} * \int_{a}^{b} f(x) d^{*} x \ddot{+} \mu \ddot{\times} * \int_{a}^{b} g(x) d^{*} x \text { for all } \lambda, \mu \in \mathbb{R}_{\beta}, \\
& \text { (2) } \quad * \int_{a}^{b} f(x) d^{*} x=* \int_{a}^{c} f(x) d^{*} x \ddot{+} * \int_{c}^{b} f(x) d^{*} x \text { for any } c \in[a, b j, \\
& \text { (3) } \quad \text { If } f(x) \ddot{\leq} g(x) \quad \text { for } r \text { all } \quad x \in[a, b \dot{]}, \quad \text { the } n \\
& \quad * \int_{b} f(x) d^{*} x \ddot{\leq} * \int_{a} g(x) d^{*} x,
\end{aligned}
$$

(4) The function $f$ is $\beta$-bounded on $[a, b j$,
(5) $\left|* \int_{a}^{b} f(x) d^{*} x\right|_{\beta} \ddot{\leq} * \int_{a}^{b}|f(x)|_{\beta} d^{*} x[10,15]$.

Remark 1 For $a \in A$, let $\bar{a}=\alpha^{-1}(a)$. Take $f$ be a function with arguments in $A$ and values in $B$, and let $\bar{f}(t)=\beta^{-1}\{f(\alpha(t))\}$. Then the following relations occur:

In Theorem 9, the highlighted text should be in italics

Theorem 9 Suppose that the following conditions are satisfied:

(i) $f$ is $*$-continuous on $[\dot{0}, a]$,

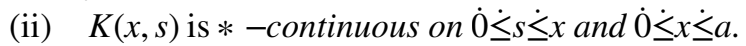

The Original Article was corrected.

Publisher's Note Springer Nature remains neutral with regard to jurisdictional claims in published maps and institutional affiliations.
The original article can be found online at https://doi.org/10.1007/ s40096-021-00427-z.

Nihan Güngör

nihanmath@gmail.com

1 Department of Mathematical Engineering, Gumushane University, Gumushane, Turkey 